\title{
Research on transportation safety of hazardous chemicals based on
}

\author{
HSE \\ Hehua $\mathrm{Li}^{*}$, Rui Zhang \\ School of Economics and Management \\ Shanghai Polytechnic University \\ *Corresponding author: Hehua Li, *hhli@sspu.edu.cn, \\ 893021359@qq.com
}

\begin{abstract}
With the increase of traffic volume hazardous chemicals, accidents in the transportation of dangerous chemicals occurred frequently, threatening the lives and property of the country and the people. In this context, based on the HSE management system, this paper summarizes and analyzes the accident factors of the transportation of hazardous chemicals logistics, and gets the key points of related accidents, With the method of HACCP(Hazard Analysis Critical Control Point), combined with the existing advanced technology, we put forward the key problem of the transportation of green hazardous chemicals logistics, In view of these key problems, a critical control point method based on HSE was worked out to ensure the green, safety, health and environmental protection in the transportation of hazardous chemicals in China.
\end{abstract}

Keywords: hazardous chemicals transportation; HSE(Health, Safety, Environment); safety system engineering; HACCP(Hazard Analysis Critical Control Point)

\section{Preface}

In daily life, the production, operation, storage, use and disposal of hazardous chemicals in every aspect of the waste cannot be separated from the transport, transport is undoubtedly become a major part of the circulation of hazardous chemicals. In the process of transportation of hazardous chemicals, the equipment may be subjected to many defects, such as defects, impact and extrusion, those containers containing flammable, explosive, toxic and dangerous goods are likely to be punctured or broken, damaged, will bring a large number of flammable, explosive, toxic and dangerous goods leakage, which led to fire, explosion, poisoning and other major accidents ${ }^{1,2}$. Coupled with a wide range of dangerous goods, the 
flow of traffic is very large, its high transport risk, wide harm, security is also particularly important, if an accident occurs, it is likely to cause great losses to the lives and property of the country and its people. Therefore, the modern hazardous chemicals logistics and transport safety management should always run through and cover the whole process of logistics, as long as any problem in the process will cause a wide range of casualties and property damage $^{3,4}$.It is very important to strengthen the safety management of dangerous chemicals transportation and the whole society should pay more attention to the problem ${ }^{5}$.

\section{The analysis on the safety of hazardous chemicals from the perspective of human- machine-ring}

With the continuous improvement of the ground transportation network, the number of vehicles is also rising, and the road traffic load pressure becomes larger. Road traffic in some cities is characterized by congestion and complexity, transport vehicles in the city on the road transport, if a little careless, will cause significant personal and property losses.

There are many reasons for the occurrence of dangerous goods transport accidents, but from the perspective of safety systems engineering, can be summarized as the following three categories: the reasons for human, mechanical equipment, the reasons for the environment, the following will analyze risk factors in the transportation of dangerous chemicals from the three aspects.

\subsection{Human reason}

People are the core factor of dangerous goods transportation accidents, and practitioners lack professional knowledge. Undocumented phenomenon is more serious. This article divides this factor into two aspects: human's unsafe behavior and imperfect management.

\subsubsection{There are 4 main aspects of human unsafe behavior:}

(1) The behavior of the loading man

(2) The behavior of the driver

(3) The unsafe behavior of the detainee

(4) The behavior of the vehicle maintenance personnel

Please see the details in Table1 
Table1-Unsafe behavior of human

\begin{tabular}{|l|l|l|l|}
\hline Loading man's fault & Driver's unsafe behavior & $\begin{array}{l}\text { Detainee's unsafe } \\
\text { behavior }\end{array}$ & $\begin{array}{l}\text { Vehicle maintenance personnel's } \\
\text { unsafe behavior }\end{array}$ \\
\hline $\begin{array}{l}\text { Overweight and super-high } \\
\text { load }\end{array}$ & $\begin{array}{l}\text { Fatigue driving or poor } \\
\text { driving skills }\end{array}$ & $\begin{array}{l}\text { Poor vehicle maintenance, } \\
\text { inspection not careful, so that } \\
\text { defective, dangerous vehicles on } \\
\text { the road }\end{array}$ \\
\hline $\begin{array}{l}\text { No fastening measures are } \\
\text { taken on the dangerous } \\
\text { goods containers to make } \\
\text { them bump or crash on the } \\
\text { road or even get out of the } \\
\text { way }\end{array}$ & $\begin{array}{l}\text { Overloading and } \\
\text { speeding }\end{array}$ & $\begin{array}{l}\text { direct the driver to } \\
\text { change the route } \\
\text { Arbitrarily }\end{array}$ & $\begin{array}{l}\text { Vehicle inspection and inspection } \\
\text { are not strictly carried out }\end{array}$ \\
\hline $\begin{array}{l}\text { The valve for the dangerous } \\
\text { goods container is not } \\
\text { tightened, resulting in } \\
\text { leakage }\end{array}$ & $\begin{array}{l}\text { Improper driving route } \\
\text { and unclear road } \\
\text { condition }\end{array}$ & $\begin{array}{l}\text { Absent without } \\
\text { official leave }\end{array}$ & $\begin{array}{l}\text { Welders illegally repair dangerous } \\
\text { goods transport vehicles in } \\
\text { flammable and explosive } \\
\text { environment , resulting in fire or } \\
\text { explosion }\end{array}$ \\
\hline$\ldots . .$. & $\begin{array}{l}\text { Careless driving on } \\
\text { changeable weather } \\
\text { conditions and } \\
\text { complicated road sections }\end{array}$ & $\ldots . . .$. & ...... \\
\hline
\end{tabular}

\subsubsection{Imperfect management}

(1) Inadequate management of government departments

Individual enterprises or drivers do not have the corresponding qualifications, but still engaged in hazardous chemicals transportation quietly, which is currently one of the important causes of frequent accidents of dangerous goods; Road transport of dangerous chemicals of public facilities is relatively backward, and long-term poor management; the state for the consequences of dangerous goods accident propaganda is not enough, especially the driver of citizen consciousness is weak, personnel violation, illegal transportation of dangerous chemical, physical chemical properties of a certain understanding can lead to the accident finally. Because the government management is not in place, which leads to the occurrence of dangerous goods accidents, therefore, how to perfect these defects can effectively control the occurrence of such accidents.

\section{(2) Enterprise management reasons}

The management deficiencies of the enterprises are mainly manifested in the lack of training and education for the safety of the drivers; the lack of inspection and repair work for the transport vehicles; the poor route and time planning of the relevant road transport; as for the 
emergency rescue work after the accident inevitably occurs, the command of the emergency rescue work is not timely and effective; for some hazardous chemicals, such as loading and unloading, carrying and packaging of products are not up to standard, and have not been corrected in time; sometimes for the sake of interests, the enterprises even allow some illegal acts, such as illegal loading and transportation, private transport and so on.

As a rule, most people's mistakes are closely related to management. It can be said that the vast majority of errors are caused directly or indirectly by management. Therefore, in order to reduce people's mistakes, fundamentally speaking, we must start with the establishment and improvement of laws and regulations, the strict enforcement of laws, the improvement of management, and the importance of training and education.

\subsection{The cause of machine}

"Machine", as the name suggests, refers to equipment and goods, therefore, "machine" is the basic factor of dangerous goods road transportation accidents.

\subsubsection{Imperfect equipment}

Logistics and transportation cannot be separated from specific equipment, tools or facilities. If these material conditions are in bad use and running state, it is likely to cause corresponding accidents. Usually, the specific causes of the vehicle or related facilities are:1)The car's chassis and other problems (such as engine, brakes, steering wheel, tire fault);(2)There are some defects in the tank itself(such as leakage of the safety valve, welding in place, loosening and so on);3)The lack or failure of Safety control components (such as the lack of good in addition to static equipment, level gauge, pressure gauge, thermometer cannot be clearly clear, etc.).

\subsubsection{The unsafe condition of transporting goods}

The unsafe condition of the goods depends on the inherent nature of the dangerous chemicals transported by the enterprise vehicles and its packaging, stacking, moisture-proof and thermal protection measures. The explosive heated or rubbed or shocked are likely to explode; compressed gas and liquefied gas at higher temperature, volume expansion, the pressure rise, may cause physical vessel rupture, causing a leak, if they encounter fire will burn or explode; if the spontaneous combustion package is damaged, spontaneous combustion will occur; if its package is damaged, it will cause spontaneous combustion when it is damp. 


\subsection{Environmental causes}

Environment is the external factor of dangerous goods transportation accident, It is mainly affected by the weather (such as rain, snow, hail, fog, wind, excessive heat etc.), terrain, traffic (such as the sharp turn, collapse accident, a huge stone block, landslides, debris flow), the density of population and transportation time and other factors, resulting in crashes, rollovers or vehicle damage.

Through the above analysis, the problems in the transportation of hazardous chemicals are embodied in health, safety and environment. At present, the more mature solution of comparing and treating this problem internationally is to through the establishment of HSE (Health, Safety, Environment) management system to solve ${ }^{6}$. But because the content of HSE management system is relatively principled and abstract, it cannot see the detailed rules and regulations. There are many employees and low degree of participation. Therefore, it is necessary to draw lessons from the theory of universal HACCP (Hazard Analysis Critical Control Point), the combination of the two can form a HSE of dangerous chemicals logistics transportation model based on critical control point.

The specific steps of the operation are first to find out the CCP(Critical Control Point) of hazardous chemicals road transportation through analysis, for the road transportation process of hazardous chemicals, the key control points are divided into before, now, after, and in the process of control in advance, in the process and after the event, we can formulate corresponding control measures from three aspects of Health (Health), safety (Safety) and environment (Environment).In this way, it is conducive to small and medium-sized enterprises' manpower, financial resources, but also help large enterprises clear staff, departments' responsibilities, to achieve full participation. Finally, it can realize the health, safety and environmental protection of the logistics transportation of hazardous chemicals.

\section{Safety measures for logistics transportation of hazardous chemicals}

\subsection{Introduction to key control point model based on HSE}

On the basis of the application of HACCP method, the key control points of hazardous chemicals transportation are divided into three categories: People (referring to the management, failure), machine (vehicle, packaging and equipment), the environment (the road), and it is not difficult to find, besides traffic and environment is the exterior objective causes, human error, vehicles, packaging and equipment and facilities are enterprise management is inseparable. So we can optimize the enterprise's management model, to 
achieve the three key control points of the effective control. According to HSE to form the key control point model shown in Fig 1.

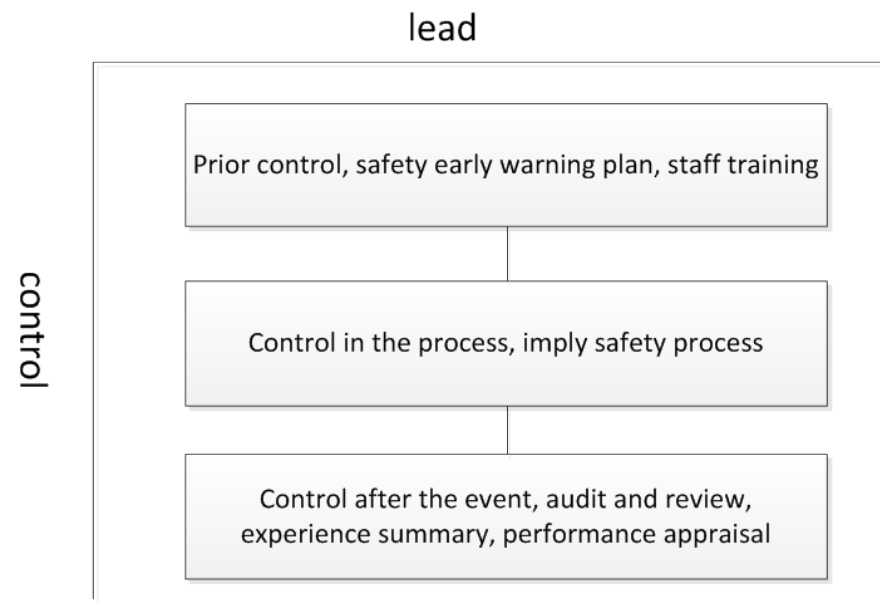

Fig.1-Critical control point model

\subsection{Safety measures for road transportation of critical control point based on HSE}

\subsubsection{Beforehand control, prevention primarily}

Any accident, as long as the work has been done in advance, the principle of "safety first, prevention first and comprehensive management”, can be avoided to the maximum extent. It can be seen that the transport enterprises should deeply understand the important role in the prevention of road transport in hazardous chemicals, especially to strengthen the vehicle management of hazardous chemicals logistics and transport enterprises.

(1) Health aspects $(H)$

People who engaged in "dangerous chemicals" use special car. The driver should obtain the qualification, know the necessary relevant chemical knowledge and the corresponding measures for the accident; The chemical production enterprises in the product before shipment should explain to the driver and the relevant personnel clearly all the cargo loading precautions, and the car ha been equipped with helmets, goggles, shovels, fire extinguishers and other emergency equipment and the "Chemical Safety Technical Manual "MSDS instructions.

The driver should have plenty of rest before driving. If the road is far away, he or she should have more drivers or arrange the resting place and the rest time for the driver in advance (mandatory).Only in this way can the driver be ensured to be in a state of full consciousness while driving, thus greatly reducing the dangerous chemicals Road traffic accidents due to the operation mistakes of the personnel. 
(2) Safety aspects (S)

a. Conduct regular vehicle inspection

The technical condition of the vehicle, the packaging of the goods and other ancillary facilities are the material basis for the safety of the driver, and these hardware facilities should be in good condition. As the transportation of hazardous chemicals, the sign must be in the specified location on the vehicle, the driver should check the vehicle's steering wheel, brake and throttle and so on are in good working condition before departure , the vehicle must not be sick on the road. The enterprise should also check for vehicles more times, identify problems and timely rectification, no driver or person to transport vehicles for illegal assembly, modification, and the problems found in the inspection must implement on the responsibility, accountability, also, the enterprise make checks at all levels, to prevent the vehicle with a "problem".

b. Create a file for the vehicle

Transport companies need to carry out their own vehicles in the transport of dangerous goods to archive, record the vehicle's various parameters, the number of years and vehicle maintenance and so on. At the same time ,a clear distinction between general trucks and hazardous chemicals transport vehicles must be made, and do the vehicle and the driver, the escort (co-drive) one by one correspondence, to avoid the general loader loaded dangerous goods on the road situation, That is, the driver can only drive the vehicle with the same qualification, and when driving dangerous chemicals vehicles, they need to carry the qualification certificate with them.

c. Install GPS and other information equipment

In addition to the development of related information technology, we should promote the application of modern information technology. Enterprises should install GPS, GPRS and RFID systems on each operating vehicle, Timely notification of irregularities in the process of driving should made and let the driver make corrections, to ensure the safety of production, to meet transportation demand, optimize logistics scheduling, reduce operating costs, improve enterprise for vehicle management, enhanced security. At the same time, the ability to monitor people, vehicles and transportation routes can also be increased, and many problems in transportation are greatly reduced.

d. Environmental aspects (E), can select reasonable routes of transportation. Choose a reasonable transport route. Through the use of risk analysis methods, hazardous chemicals Road transport accident frequency and consequences of scientific assessment, take appropriate measures in 
advance to reduce the possibility of transport accidents; On the other hand, the choice of reasonable transportation routes can reduce the number of kilometers of vehicles, thereby reducing the emission of automobile exhaust, helping enterprises to achieve the goal of reducing carbon emissions, and protecting the environment.

\section{e. Establish an integrated emergency platform}

Enterprises who engaged in hazardous chemicals Road transport should formulate scientific, perfect and feasible contingency plans, equipped with protective equipment and rescue, and seriously organize drills, constantly improve the emergency response plan. Enterprises should also establish a safe transport card system, and do a good job in many aspects of the accident settlement measures.

More and more new technologies and materials are applied to vehicles, such as GPS, RFID equipment, etc. The requirements for safe operation are becoming higher and higher, and the inspection of the condition of the vehicle, the inspection of the goods and other facilities and equipment should gradually be scientific, normalized and standardized, The simple use of crude tools, only rely on the experience to judge, it is difficult to meet the requirements of safety operation, only inspection items, accuracy, depth continuing to progress, can this way fundamentally eliminate car accidents due to the technical condition of the vehicle, the packaging of goods and other auxiliary facilities of the deterioration of the issue. The emergency platform can help us solve some unexpected situations which have not been taken into consideration before, and ensure that effective measures can be taken in time when the emergency occurs, and the losses will be reduced to the minimum. The prevention system is shown in Fig 2.

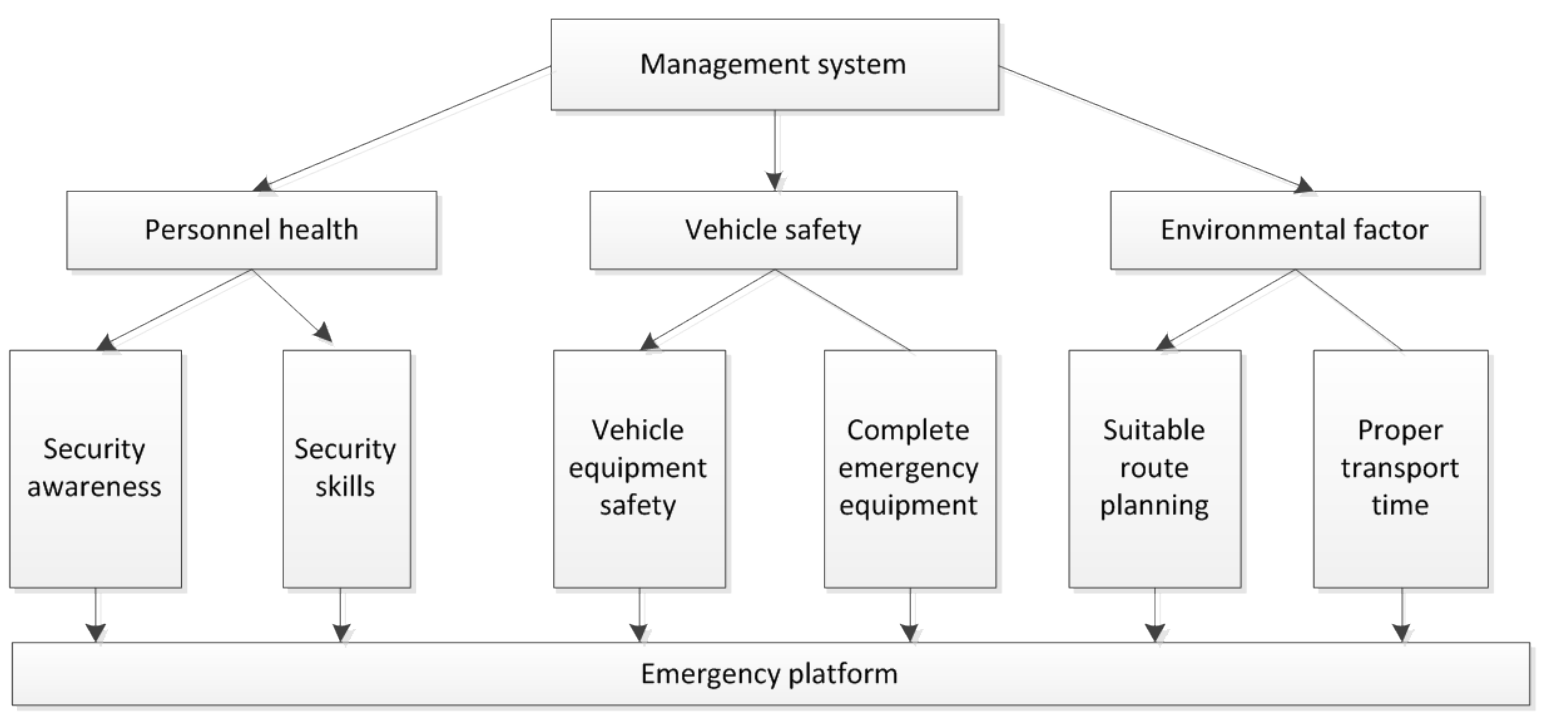

Fig.2- Preventive architecture chart2) Control in time, effective in time 


\section{(1)Health aspects $(H)$}

The quality of transportation personnel determines the whole process of transportation of hazardous chemicals. Transportation personnel safety quality is low, the transportation of dangerous chemicals quality is not be understood, these behavior in the transportation process will be more likely lead to illegal operation, increasing security risks. Similarly, after the accident, the transport personnel do not have the appropriate safety knowledge, it cannot effectively deal with the accident. Even with the transportation of dangerous chemicals, enterprises should also monitor their own personnel and vehicles in real time and understand all the dynamics of transportation.

\section{(2)Security aspects(S)}

Make full use of RFID and 3G (GPS / GPRS / GIS) technology, the static management information of hazardous chemicals road transportation can be effectively integrated with vehicle information management, Through the vehicle identification, we can make remote transmission of hazardous materials logistics transport process's static information, build a database, achieve dangerous goods logistics transport security of static information management, conduct real-time monitor, lead the dynamic path optimization model and geographic information system fully integrate ,The real-time traffic information collection and automatic vehicle location system can provide real-time input for the dynamic path optimization model, the minimum harm and the shortest transit time and other factors will be reflected in the model, in order to update the line at any time.

\section{(3)Environmental aspects (E)}

An enterprise can imply oil saving, KPI assessment methods, on one hand these ways can save the transportation cost, on the other hand can also reduce vehicle emissions, thereby reduce carbon emissions, protect the environment, make the hazardous goods logistics gradually move closer to the direction of green logistics.

\subsection{Afterwards evaluation, management}

In the process of transportation, not only can enterprises prevent in advance, monitor in transit, when the accident occurred, but also can do elevation for the accident causes, remedy, by the pursuit of innovation in a summary, the enterprise will achieve a breakthrough. The enterprise may revolve around the existing HSE management system, unifies own actual situation, formulates the transportation management method conformed to the enterprise itself, realizes the green, the health, the safe transportation environment. 


\subsubsection{Health aspects $(H)$}

Management team should look for hazardous chemicals' deficiencies in the road of transport process management. Because of the continuous development of the enterprise itself and the change of the external environment, there may be a certain deviation between the management objectives, management procedures, management methods and management results. Therefore, we need to timely examine, review the compliance, validity and applicability of the management system, adjust the reality and the system does not match, the system and the reality does not adapt to the part, to achieve continuous improvement, the purpose of continuous improvement. Encourage front-line staff to participate in operational management. Since drivers are always in the first place in the transportation of dangerous chemicals, the information they have is the most accurate. Therefore, their suggestions will be of great help to the improvement of the work in the future. On the other hand, enterprise should be concerned about the front-line operators, especially the driver, do a good job performance appraisal work, employees in the completion of dangerous chemicals road transport process, managers will promptly tell employees their safe working behavior or unsafe work behavior, affirm the safety behavior of employees, the insecure behavior should be properly guided and educated.

Enterprises should do well in humanistic care and pay attention to their occupational health. Due to the transportation of hazardous chemicals work pressure, the risk factor is high. The enterprises should regularly carry out various humanistic care activities, such as hold basketball, organize the staff to see the film, also contains regular organization of medical staff, to ensure the health of employees.

\subsubsection{Security aspects(S)}

Vehicle inspection, packaging and equipment, according to the specific process of transportation vehicles, and related traffic data, examination of vehicles, packaging and facilities for security problems, should be repaired or replaced. For example, to tank car inspection, the tank top safety valve detection, tank tightness test, the remaining valve tightness tests, whether the body logo is obvious. Check the safety helmet, goggles, shovels, fire extinguishers and other emergency equipment is missing, if missing, then equipped with integrity again. 


\subsubsection{Environmental aspects (E)}

Optimizing the route, for the route, we should also according to the results of the operation to re-examine whether it is a reasonable route, whether there is the possibility of optimization, thereby saving the cost of transport process and reduce carbon emissions during transport, thereby reducing environmental pollution.

Review the transportation process of hazardous chemicals, people should check whether hazardous chemicals run, permeate, drip, leak, etc., and if so, whether the chemicals are handled properly, whether the pollution to the environment will be minimized. This will help us to cope with similar situations in the future, and we can take measures more effectively to fulfill corporate responsibility and achieve environmental protection.

\section{Conclusion}

The transportation of hazardous chemicals in our country is still in the immature stage, and there are many defects in the transportation process, which can easily lead to the occurrence of traffic accidents, and the consequences are often unimaginable. From the perspective of China's logistics transportation of hazardous chemicals, using the HACCP method, this passage will find out the dangerous chemicals logistics transportation safety from 3 key points: management, human error, vehicles, and packaging equipment and facilities, traffic and environment. Referring to the advanced HSE management system, based on the HSE management system model, fusing method of HACCP, this passage found 3 critical control points of dangerous chemicals logistics transportation management, finally from the health, safety and environment these three aspects to develop methods of key control points. This model can help the transportation of hazardous chemicals to achieve the goal of "zero accident", thus help to reduce the damage to people caused by hazardous chemicals transportation and reduce the pollution to the environment, Finally, the realization of peopleoriented, health first, safety first, prevention, scientific management, environmental quality, all can ensure the health, improve economic benefits, social benefits, environmental benefits, create a road of virtuous cycle and sustainable development of dangerous chemicals logistics transportation.

\section{Acknowledgement}

This research was financially supported by the Foundation of Subject of Management Science and Engineering (XXKPY1606) of Shanghai Polytechnic University. 


\section{Reference}

1. L. Y. Yan, Y. G. Chen, Study on new characteristics and the countermeasures of road transportation accident of hazardous chemicals.[J]. Journal of Science and Technology of Safety Production in China, 2010.8

2. L. Ling, J. J. Meng, L. Y. Yu, Current emergency causation hazardous chemicals larger bridges transportation of Jiangsu Province. [J]. Communications Standardization, 2010.24

3. Y. X. Chen, An analysis of traffic safety and pollution accidents of dangerous goods [J]. Environmental Protection and Circular Economy, 2015.8

4. K. Y. Li, Discussion on emergency rescue of dangerous chemicals transportation accident [J]. Safety, Health and Environment, 2010. 10(2)

5. Y. G. $Q u$, Thoughts and suggestions on safety management of road dangerous goods transportation [J]. Logistics Technology, 2010(01)

6. H. H. Li, Health, safety and environmental management of Chemical logistics [M]. Shanghai University of Finance and Economics Press CO. LTD, 2013. 